Cite: Taks, M., Green, B.C., Misener, L., \& Chalip, L. (2016). Sport events and residential happiness: The case of two non-mega sport events. Journal of Global Sport Management. 1(3-4), 90-109. DOI: 10.1080/24704067.2016.1231925.

\title{
Title: Sport Events and Residential Happiness: The Case of Two Non-Mega Sport Events
}

\begin{abstract}
This contribution explores whether the hosting of two non-mega sport events affected the happiness of residents (non-attendees) in the host community, and if these feelings differed according to the type of event. The events under investigation were two multi-sport events held in the same community: the Ontario Summer Games and the 55+Summer Games. Residents were intercepted in public spaces to complete a survey, including levels of happiness, event and sociodemographic variables. Happiness was measured in a holistic way, including: overall happiness, satisfaction, positive and reversed negative affect dimensions of subjective well-being. Hierarchical regression analysis revealed: (1) higher levels of happiness for aware, non-attendee residents when measured with a single-item of overall happiness, but not for other measures of happiness in the holistic approach (causality can not be confirmed); (2) aware, non-attendee residents did not need to have the intention to attend the events to experience these higher levels of happiness; and (3) higher feelings of happiness of aware, non-attendee residents were not different according to the type of event. From a practical perspective, these findings stress the importance of informing residents of these events so they become aware that these events are being hosted in their community. Effective communication should include feelings of pride and belonging, as these are expected to stimulate feelings of happiness of non-attendee residents.
\end{abstract}

Keywords: Hierarchical regression analysis; Negative affect dimension; Positive affect dimension; Satisfaction, Subjective well-being. 


\section{Introduction}

The economic impact of sport events has come under scrutiny. Sport economists like Kavetsos and Szymanski (2010) claim that sport events do "not make us rich, but that they will make us happy" (p. 160). Since sport events have an apparent "feel-good effect" (e.g., Maennig \& Porsche, 2008), it is worthwhile to accurately capture feelings of happiness in the context of events. Most research analyzing the relationship between sport and happiness is related to active participation in sport (e.g., Dewar \& Kavussanu, 2011; Downward \& Rasciute, 2011; Rodriguez, Kesenne, \&Humphreys, 2011). Findings regarding the relationship between elite sport success and happiness are inconsistent (e.g., Davis \& End, 2011; Hallman, Breuer, \& Kuhnreich, 2013). Furthermore, the link between sport events and happiness is far less understood. Few studies have analyzed this relationship, and the majority of these studies have mainly focused on mega sport events (MSE). For example, Kavestos and Szymanski (2010) found that the "feel good effect" from the World Cup was stronger than for Olympic Games. However, the longevity of this feeling is questioned (Maennig \& Porsche, 2008) and little is known about the potential of non-mega sport events (NMSE) to create a comparable feeling of happiness among residents in host communities.

The focus of this study is on feelings of happiness of residents who are aware (or supportive) of an event, but who do not necessarily attend the event. Thus, the feelings of happiness measured in this context should not be confused with the higher levels of happiness residents may experience when actually attending an event (e.g., Hallman et al., 2013; Kuper \& Szymanski, 2012; Maennig \& Porsche, 2008; Mutter \& Pawlowski, 2014). Therefore, a different and more holistic approach to measuring happiness is proposed in this particular context. Thus, the purpose of this paper was to investigate whether the hosting of two NMSE impacted the happiness of non-attendee residents, and if reports of happiness differed according to the type of 
event the non-attendee residents were most familiar with.

First, we define happiness and related terms. We then explore the relationship between leisure and happiness, and elaborate on the scarce literature, which links sport events with happiness. We subsequently discuss other relevant factors known to influence reports of happiness. The two NMSE that form the context for this study are described at the beginning of the method section. Results are provided and discussed after which conclusions are formulated regarding whether financial expenditures on sport events can be justified based on enhancing feelings of happiness among host residents.

\section{Literature Review}

\section{Conceptualizing Happiness}

The concept of happiness has received attention from researchers for decades in a variety of fields (Rodriguez-Pose \& von Berlepsch, 2014). Happiness has been defined, conceptualized, and labeled with various terms in the literature. The concept of happiness is frequently considered either synonymous or closely associated with terms such as "well-being" (e.g., Davis \& End, 2011; Han, Kim, Lee \& Lee, 2013), “individual welfare” (e.g., Kavetsos, 2011), "life satisfaction" (e.g., Zhou, 2012), and "quality of life" (e.g., Huang \& Humphreys, 2011). Diener (2000) defined and explained subjective well-being (SWB), which is sometimes labeled "happiness" in colloquial terms, in the following manner:

SWB refers to people's evaluations of their lives - evaluations that are both affective and cognitive. People experience abundant SWB when they feel many pleasant and few unpleasant emotions, when they are engaged in interesting activities, when they experience many pleasures and few pains, and when they are satisfied with their lives. (p. 34)

Although happiness is a concept that has received a great deal of attention from 
researchers, there have been several criticisms of the happiness literature. For example, Kavetsos and Szymanski (2010) stated that terms such as "happiness" and "satisfaction" might have different interpretations across various languages, cultures, and populations. As such, standardized measurement tools may not sufficiently account for cross-cultural differences. Similarly, Joshanloo (2014) investigated and detailed differences in the conceptualization of happiness between Western and Eastern schools of thought. For example, individualistic societies define "the good life" quite differently than collectivistic societies due to conflicting values about the importance of one's individual self (Joshanloo, 2014). Despite these potential differences, some studies have found that SWB is a universally understood concept. For example, one study of 7,204 college students in 42 countries found that even in non-Westernized societies, respondents reported happiness and life satisfaction as being very important and given frequent thought (Diener, 2000). As such, it is possible that although exact definitions and conceptualizations of happiness might vary between cultures, SWB appears to be a concept that is understood and deemed important by individuals around the world.

SWB is considered to be comprised of various components, including overall life satisfaction, satisfaction with important domains (e.g., career), frequent positive affect (emotions), and low levels of negative affect (Diener, 2000). For the purpose of this study, we used the conceptualization of SWB proposed by Diener (2000), which include the following four components of SWB as measures of happiness: (1) overall happiness, (2) satisfaction with important life domains, (3) high frequency of positive affect, and (4) low levels of negative affect.

\section{Leisure and Happiness}

Previous research suggests that sport events (participation and spectating) have the potential to increase individuals' happiness by affecting one or more component of SWB. 
However, the specific ways and conditions under which this effect occurs are not always clearly articulated. Mannell and Snelgrove (2011) explained that the effect of increasing SWB by pursuing leisure (e.g., participating in or spectating a sport event) could be explained by at least one of following theories: creating opportunities for individuals to experience pleasure and fun, keeping individuals busy, developing and confirming identities tied to the activity, encouraging personal growth, and serving as a resource for coping with stress. Some of the extant literature on the hosting of sport events and their impact on host residents' happiness seems to fit well into the theories of creating opportunities for pleasure and fun, keeping individuals busy, and developing and confirming identities tied to the activity (Mannell \& Snelgrove, 2011). The encouragement of personal growth has received some attention through the experiences of local volunteers at the events (Snelgrove, Wood, \& Havitz, 2013; Misener, Doherty, \& Hamm-Kerwin, 2010; Taks, Green, Misener, \& Chalip, 2014; Thoits \& Hewitt, 2001). As well, the notion of coping with stress by attending events has received minimal attention, and has focused mostly on attendance and travel as an escape for tourists (Shipway \& Jones, 2007; Snelgrove, Taks, Chalip, \& Green, 2008).

Building on this notion of relevance of the sport or sport events, it can be assumed that individuals, who attend and spectate the events, do find some relevance in this attendance. As such, event attendance (or intention to attend) could trigger happiness through any of the mechanisms identified by Mannell and Snelgrove (2011). Previous studies on sport events and happiness have not made a distinction between event attendees and non-attendees. It can be assumed, however, that sport events impact residential happiness in different ways and degrees based on event attendance. Thus, we suggest that there is another mechanism not identified by Mannell and Snelgrove (2011) responsible for explaining the connection between sport events and happiness for non-attendees. Specifically, the literature on sport events seems to suggest that 
happiness for non-attendee residents may be triggered through enhanced community or national pride (e.g., Gibson, Walker, Thapa, Kaplanidou, Geldenhuys, \& Coetzee, 2014; Gursoy, Chi, Ai, \& Chen, 2011; Pranic, Petric, \& Cetinic, 2012). Furthermore, the effects may differ between those who attend the event, those who watch from afar, and those who do not attend but are aware of the hosting of the event.

\section{Community and national pride through event hosting.}

Kavetsos and Szymanski (2010) used data from a single-item well-being question within the Eurobarometer survey for 15 separate major tournament hosts between 1974 and 2004. These authors found that hosting a major soccer event (e.g., FIFA World Cup, European Championship) had a significantly positive effect on the happiness of the host country's residents, except in the United Kingdom. Furthermore, these authors found that this "feel-good" effect was significant for all age and gender groups, however, it was only sustained long-term after a World Cup (i.e., for the subsequent two to four years following hosting a World Cup). Additionally, this effect was not significant for countries hosting an Olympic Games. In fact, Kavetsos and Szymanski (2010) found a significantly negative impact on residential happiness four to six years following hosting an Olympic Games. In a case study on the 2006 FIFA World Cup, Maennig and Porsche (2008) wrote of a significantly noticeable "feel-good" effect in the host country Germany. This effect was enhanced by the unexpected success of the German national team, which led to heightened patriotism and national pride. However, this effect was not sustained long-term as the display of national symbols in Germany has reverted to pre-World Cup levels (Maennig \& Porsche, 2008). Gibson and colleagues (2014) reported an increase in psychic income (i.e., a feeling of event-related pride and euphoria) eight months post the FIFA 2010 World Cup in South Africa, while feelings of social cohesion decreased or stayed stagnant. Thus, there is some support that hosting a sport event has at least a short-term positive effect on the well-being and 
happiness of local residents.

Developing and confirming identities through event hosting. There is support for the notion that participating in or spectating sport events contributes to the development and confirmation of identities (Green, 2001; Snelgrove et al., 2008; Snelgrove \& Wood, 2010). Thus, when an event is highly relevant to an individual it will likely elicit stronger feelings of personal expression and social connection with similar others. The more affinity people have with sport, the greater the likelihood that they are willing to engage, spend time and/or money on sport events (e.g., in the form of intention to attend the event). Events are therefore more likely to affect their personal level of happiness.

Also related to identity development through sport events, Kuper and Szymanski (2012) found that in almost every European country that was analyzed based on available data, the rate of suicide in each country was significantly reduced when their respective national soccer team was playing in either a World Cup or UEFA Championship. For example, the largest country in the study, Germany, experienced their suicide rate peak in May and June. However, in the months of June when a major soccer tournament was held $(1992,1994,1996)$, there were approximately 30 less men and 14 less women who committed suicide, which constituted a significant decrease (Kuper \& Szymanski, 2012). As such, it seems as though the universal appeal of these major soccer events creates a feeling of community and togetherness that allows typically isolated individuals to feel connected to something. This feeling is often referred to as "social cohesion" and can significantly increase quality of life and well-being (e.g., Heere et al., 2013; Kaplanidou et al., 2013; Klein. 2013). However, the FIFA 2010 WC decreased or did not affect feelings of social cohesion post event as indicated earlier (Gibson et al., 2014). Thus again, the results are mixed.

Sport events, happiness and non-mega sport events. Note that all empirical examples 
discussed here regarding the happiness of host residents pertain to MSE. Except for short-term social impacts such as social cohesion, community engagement, and community pride (e.g., Heere, Walker, Gibson, Thapa, Geldenhuys, \& Coetzee, 2013; Inou \&Havard, 2014; Taks, 2013), no research to date has investigated if NMSE affect general feelings of happiness and well-being among host residents, and will be explored here.

Temporal effects of happiness. Findings on the longevity of increased happiness created through sport events are inconsistent. Even though Kavetsos and Szymanski (2010) found some support for a long-term increase in happiness after hosting a World Cup, these authors stated that, "in our view these results do not justify the inference that hosting events creates anything more than a short term feel-good factor" (p. 167). When Kuper and Szymanski (2012) repeated the

study, the authors used data from several large databases instead of one and tested the effect of hosting a major soccer tournament after controlling for additional factors related to happiness. Five separate tournament hosts were sampled for which all desired data were available. The authors found that hosting a major soccer tournament resulted in an increase in reported happiness of the host country's residents. Furthermore, this effect was sustained long-term for the subsequent two to four years following hosting a World Cup, however, there was no lasting effect found one year after hosting a European Championship. As such, these findings duplicate the results found by Kavetsos and Szymanski (2010), but contrast Maennig and Porsche's (2008), who claim that positive effects from hosting a World Cup are not necessarily sustained longterm. Cleary, there is a need for additional investigation into the sustainability of increased happiness after hosting a sport event.

\section{Determinants of Happiness}

There are a number of factors that can predict happiness among individuals. Two widespread factors are socio-demographic characteristics, local and external conditions, such as the weather. 
Socio-demographic characteristics. Socio-demographic variables have been shown to impact happiness in predictable ways through pre-determined relationships. Among the most commonly mentioned variables are: age, marital status, income, employment status, gender, education level, ethnicity, health status, and local external factors (e.g., Downward \& Rasciute, 2011; Pawlowski et al., 2011; Rodriguez-Pose \& vonBerlepsch, 2014).

Age is considered to have a "U-shaped" relationship with happiness, whereby individuals typically decrease in happiness until approximately 30 years old, and then notice their SWB increase as they age. In terms of marital status, married individuals are typically happier than single or divorced individuals (e.g., Downward \& Rasciute, 2011; Kavetsos \& Szymanski, 2010; Rodriguez-Pose \& vonBerlepsch, 2014). Furthermore, employed individuals are typically happier than those unemployed (e.g., Downward \& Rasciute, 2011; Forrest \& McHale, 2010; Kavetsos \& Szymanski, 2010; Rodriguez-Pose \& vonBerlepsch, 2014), a higher level of education is usually associated with increased happiness (e.g., Kavetsos \& Szymanski, 2010; Rodriguez-Pose \& vonBerlepsch, 2014), and females usually report higher levels of SWB than males (e.g., Kavetsos \& Szymanski, 2010; Rodriguez-Pose \& vonBerlepsch, 2014). Additionally, health status is positively related to happiness (e.g., Forrest \& McHale, 2010; Kavetsos \& Szymanski, 2010; Pawlowski et al., 2011), visible minorities are usually less happy than Caucasian (e.g., Forrest \& McHale, 2010; Pawlowski et al., 2011), and personal income relative to one's peers also affects happiness (e.g., Downward \& Rasciute, 2011; Forrest \& McHale, 2010; Kavetsos \& Szymanski, 2010; Rodriguez-Pose \& vonBerlepsch, 2014). By controlling for these types of sociodemographic variables, researchers can reduce bias and interpersonal incomparability when investigating impacts on SWB.

Sport events, happiness and socio-demographic characteristics. Although the above findings give merit to the claim that hosting a sport event has the potential to positively impact 
residential happiness, there have also been some negative implications. For instance, Brown and Massy (2001) highlighted significantly lessened well-being for those in lower socio-economic classes in the host city (Brown \& Massey, 2001). Kuper and Szymanski (2012) found that even though the overall level of happiness in the host country increased, women did not become any happier. As such, nearly half of the population may not see their happiness increase at all if their home country hosts a MSE. It should be noted, however, that this finding contradicts the results of Kavetsos and Szymanski (2010) who found that happiness was increased across all age and gender groups, and also Hallmann et al. (2013), as their study found that women actually experienced a larger increase in happiness than men when their respective national athletes performed well.

Sport events, happiness and local conditions. Some authors have identified other external factors (Downward \& Rasciute, 2011; Forrest \& McHale, 2010), or the weather (Connolly, 2013), or select local and geographical conditions such as the level of inflation or inequality; the latter both negatively affect happiness scores (Rodriguez-Pose \& vonBerlepsch, 2014). For instance, Kuper and Szymanski (2012) found that local community residents reported significantly lower levels of happiness four to six years prior to hosting a sport event. This decrease was likely due to the enormous stress and uncertainties that surround the planning and organization of MSE (Kuper \& Szymanski, 2012c). Moreover, although increasing the happiness and well-being of citizens may be a goal of many governments around the world, developing countries have to re-distribute significant funds from sectors such as health care and education to host a MSE. Thus, Kuper and Szymanski (2012) claimed that the huge investment required to host a mega soccer tournament (even if its purpose is to increase residential happiness) is not worth the investment for developing countries. In addition, numerous studies reveal negative social impacts resulting from hosting MSE, and regulations by sport governing bodies (i.e., the 
International Olympic Committee) to regulate social impact planning to protect the well-being of the host residents are rarely implemented in practice (e.g., Gaffney, 2013; Holmes et al. 2015). Thus, there is also evidence that hosting a sport event (specifically MSE) can negatively impact the well-being of local residents. As far as weather is concerned, Schwarz and Clore (1983) found that respondents surveyed on sunny days reported higher life satisfaction scores than those surveyed on rainy days. In a similar study, Connolly (2013) found that weather on the day of an interview significantly affected general life satisfaction scores, but only for women (men were unaffected). Specifically, this author found that higher amounts of rainfall and hotter temperatures on days in summer months significantly lowered female happiness scores. While these external conditions can affect responses concerning life satisfaction, we will not consider them here, given that the data collection process was fairly constant in terms of socio-economic (i.e., same region) and weather condition (i.e., same moth), as well as the protocol.

Thus, the purpose of this study was to explore: (1) if two NMSE affected the happiness of in the host community; and, (2) if feelings of happiness of non-attendee residents differed according to the type of event they were most familiar with, while taking into account relevant, sport event related and socio-demographic variables.

\section{Method}

\section{Context: Two Non-Mega Sport Events}

Data were collected in the context of two NMSE: the 2014 Ontario Summer Games (OSG) hosted in a medium-sized city in Canada, and the 2014 Ontario 55+ Summer Games $(55+\mathrm{SG})$, hosted by the same city in collaboration with a neighboring municipality. These events took place in the same summer, two weeks apart. The OSG is a provincially based competition, held on even-numbered years. Communities engage in a bidding process for the opportunity to host the Games. The 2014 event involved 19 different sport competitions such as soccer, 
baseball, basketball, archery, box lacrosse, and skeet shooting. It attracted 2100 athletes ranging from 13 to 20 years old (Waddell, 2014, Aug. 7). The 55+SG unites participants aged 55 years and above in a multi-sport environment. The 2014 competition was spread over two days with approximately 1400 athletes competing in 18 sports (http://www.ontario55plus summergames.com).

While both events received some media attention, it was far less than the media attention the 2013 International Children's Games (ICG) had received in the preceding year, which took place in the same city as the OSG and 55+SG (Taks, Wood, Snelgrove, \& Anderson, 2014). In contrast, the hosting of the 2014 OSG actually received some negative publicity, as the city was "picking up the slack" because another city, which had initially won the bid to host the OSG, backed out last minute because they refused to be liable for the deficits (i.e., the costs to host the Games were simply to high; Prince, 2013, October 11). While there was some media attention, the festival atmosphere (e.g., Chalip, 2006) created around both events (OSG, 55+SG) was rather limited.

\section{Sample and Data Collection}

In order to collect data from community residents who did not attend the events, passersby (18 years old and above) were approached in two public places in the host communities. A total of 618 questionnaires were collected on six days over a period of three weeks in August 2014. This was around the time the events were hosted, ranging from one week prior, during, and one week after the events. Of the 618,447 cases $(72 \%)$ were usable for further analysis. However, another 126 observations were excluded for further analysis, namely those who where aware that events were taking place, but refrained form indicating from which event perspective (OSG or $55+\mathrm{SG})$ they were answering the questionnaire $(\mathrm{n}=77)$, and those who answered the questionnaire form an event perspective, but were unaware that the event took place 
before filling out the questionnaire ( $n=44$ for $O S G$, and $n=5$ for $55+S G$ ). Thus, the total number of usable observations for further analysis was $\mathrm{N}=321$, consisting of the following three distinct groups: (1) aware of the OSG taking place in the host community $(n=176),(2)$ aware of the $55+\mathrm{SG}(\mathrm{n}=52$ ), and the control group (absence of event perspective, and unaware of any event taking place; $n=93$ ). Data were collected electronically (via a tablet), but paper surveys were also available upon request.

\section{Survey and Measurements}

The survey consisted of three sections (21 questions, 90 items): a happiness, an event, and a socio-demographic section.

Happiness measurements. Since individuals may differ in their personal understanding of happiness and well-being, the survey started with a vignette (based on Hopkins and King's (2010) recommendation) to contextualize the concept of well-being and happiness and to overcome interpersonal incomparability. A hypothetical individual was described with a theoretically high level of SWB, as follows: "Sam is an outgoing person who enjoys having a secure career, loving home, and good health. Sam is frequently cheerful and rarely upset regardless of what is going on. Overall, Sam is satisfied with his/her life". Respondents were asked to rate Sam's level of happiness on a scale from 1 to 6 , with 1 being 'not at all happy' to 6 being 'very happy' (HAP_Sam). Rating the happiness of a hypothetical individual primes the respondent to rate their personal level of happiness in a similar manner (Hopkins \& King, 2010).

Using the same 6-point Likert scale, respondents were subsequently asked to rate their own level of overall happiness based on the following question: "Taking all aspects of your life into account, please select your current level of overall happiness" (HAP_You). Several studies, which explored the relationship between sport and happiness, have relied on this single-item measure to capture happiness (e.g., Davis \& End, 2011; Kavetsos \& Szymanski, 2011). 
Although a variation of this single-item happiness measure is frequently the sole item included in sport and happiness research, a more holistic understanding and measurement of happiness and well-being was desired for this study (see also Littlejohn, Taks, Wood, \& Snelgrove, submitted). Therefore, following the vignette and the general well-being question, another component of SWB, namely satisfaction with important domains (i.e., "rate you current level of satisfaction with each of the following domains"), was captured with three items measuring satisfaction with: "life at home", "health status", and "employment situation"; using a four-point Likert scale ( $1=$ "Not at all satisfied" to 4 = "Very satisfied"; Connolly, 2013). A category of "Non Applicable" was also included. This value was replaced with the average value for that item in order to limit the number of missing cases. EFA revealed one factor with an eigenvalue of $1.77(\mathrm{VE}=59 \%)$ and an inter-reliability score for the three items revealed a Cronbach's Alpha of .64, which is under the commonly accepted value of .70. However, Kilne (as cited by Field, 2009) indicated that values below .70 can be expected when dealing with psychological constructs given the diversity of the constructs being measured. Subsequently, the item scores for the subscale were averaged to form an aggregate, representing overall satisfaction with life (SATIS).

Other components of SWB include frequent positive affect and reversed negative affect, which were captured using a measurement of affect dimensions (Kahneman, Krueger, Schkade, Schwarz, \& Stone, 2004). This section provided respondents with an opportunity to specify what emotions they had experienced within the last week ("How have you generally felt during the past week?"). The three positive emotions included: happy, warm/friendly and enjoying myself; the five negative emotions were: frustrated/annoyed, depressed/blue, hassled/pushed around, worried/anxious, and tired. Each specific emotion was rated on a six-point Likert scale $(0=$ "Not at all" to $6=$ "Very much"). For further analysis, the negative affect dimensions were reversed, 
thus operationalized as reversed negative affects. EFA on the eight items confirmed the existence of the two constructs. The five items of the reversed negative dimensions loaded high on the first factor $(E V=2.97 ; \mathrm{VE}=37 \%, \alpha=0.78)$. Subsequently, the five individual item scores were averaged to form an aggregate, which represents the reversed negative affect construct (SWB_Neg_R). The three items reflecting positive affect loaded on the second factor $(\mathrm{EV}=1.81$; $\mathrm{VE}=23 \%, \alpha=0.76)$. The item scores for this scale were averaged to form an aggregate, which represents the positive affect construct (SWB_Pos).

Event variables. These variables include event perspective and awareness, and the variable "intention to attend the event". The three distinct groups outlined in the sample above are core to this study, and represent event perspective and awareness. For the regression analysis, each category was transformed into dummies, with the control group being the reference group, as follows: OSG_D (dummy) are the participants who filled out the questionnaire from the perspective of the OSG, and were aware that these games were hosted prior to filling out the questionnaire; FFSG_D (dummy) are the participants who filled out the questionnaire from the perspective of the 55+SG, and were aware that these games were hosted prior to filling out the questionnaire; Contr_D (dummy; reference group), these participants had no event perspective and were non-aware that events were taking place. Intention to attend the events was measured by asking participants whether or not they plan to attend the event (ATTEND; dummy variable with $0=$ not planning to attend, and $1=$ planning to attend).

Socio-demographic variables. Age (AGE) was measured as the average age of the participants. Sex (SEX) was operationalized as a dummy variable $(0=$ male and $1=$ female $)$. Relative income (INC) was measured using an ordinal scale, based on the question "Making ends meet with my current total disposable household income is (check one)": 1=Very difficult; 2=Difficult; 3=Somewhat difficult; 4=Somewhat easy; 5=Easy; 6=Very easy. Ethnicity was 
measured as a dummy variable (E_Cauc: $0=$ Non-Caucasian and 1=Caucasian). Three categories were established for household status: 1=single (HH_Single); 2=married no kids (HH_MNK), 3=married with kids (HH_MWK).

\section{Data Analyses}

Descriptive statistics were first calculated. Anova's (for continuous variables) and Chisquare analyses (for categorical variables) were performed to test differences between the three event awareness groups (OSG, 55+G, Control). EFA was performed to reduce the data for the Happiness variables that included multiple items (e.g., SATIS and SWB). Finally, hierarchical regression analyses were executed to detect if the NMSE under investigation affected the reports of happiness among R-NEA, and whether the two different types of NMSE affected happiness of R-NEA in different ways. Four models of hierarchical regression were tested, one for each happiness construct (HAP_You, SATIS, SWB_Neg_R and SWB_Pos; i.e., the dependent variables). In step one, all relevant socio-demographic (sex, age income, ethnicity and marital status) as these factors have been shown to affect the rating of happiness (e.g., Downward \& Rasciute, 2011; Pawlowski et al., 2011; Rodriguez-Pose \& vonBerlepsch, 2014). In step two, the event variables were entered, namely the event perspective and awareness groups (OSG_D and 55+SG_D, with the control group being the reference group), and the intention to attend the variable (ATTEND).

\section{Results}

\section{Descriptive statistics}

Table 1 provides an overview of all variables included in the analysis. The average age of the participants was $37(S D=17)$. Respondents in the 55+SG group were significantly older $(M=52, S D=17)$, compared to the OSG group $(M=36$ years, $S D=15)$, who in turn were significantly older that the control group $(M=30$ years, $S D=16 ; \mathrm{F}(2,318)=35.97, \mathrm{p}<.001)$. The 
majority of the participants were women (58\%), however, for the 55+SG group, sex was almost equally distributed (52\% women). The average response on relative income was $3.68(S D=1.24)$, representing a score somewhere between "somewhat difficult" (=3) and "somewhat easy" (=4). Caucasians dominated in all three groups (77\% overall), especially in the $55+$ SG group (87\%). The 55+SG group consisted of significantly fewer single people (37\%; Chi-sq=9.78, p<.05) compared to the two other groups (56\% overall), although not significant, more of the 55+SG group were married with kids (46\% compared to $34 \%$ overall). About $27 \%$ of all participants indicated that they planned to attend the event. Again the 55+SG group stood out as $44 \%$ indicated they were planning to attend (Chi-sq=17.56***).

With regard to the happiness variables, as expected, all three groups rated Sam's happiness relatively high with an average score of $5.26(S D=0.71)$ on a scale from 1 (=not happy at all, to $6=$ very happy). No significant differences appeared between the three groups in their ratings of the vignette, indicating a similar understanding of the concept of SWB. The 55+SG reported higher levels of overall happiness $(M=5.15, S D=0.89)$ than the control group $(M=4.64$, $S D=0.90)$. The average for the overall happiness of the OSG group $(M=4.92, S D=0.89)$ was not significantly different from either group $(\mathrm{F}(2,318)=5.740, \mathrm{p}<.01)$. The $55+\mathrm{SG}$ group also scored significantly higher scores on the reversed negative affect $(M=4.11, S D=1.09)$ than both, the OSG $(M=3.60, S D=1.22)$ and the control group $M=3.62, S D=1.31 ; \mathrm{F}(2,318)=3.724, \mathrm{p}<.05)$.

No significant differences appeared in the three groups with regard to satisfaction with life; the average for the three groups was $3.18(S D=0.56)$. Note, however that this construct has the lowest overall scores, which can be explained by the fact that it includes three life domains (home, health and employment). Positive SWB, also did not reveal significant differences between the three groups, but clearly showed higher scores around $4.5(S D=1.05)$. 


\section{Predictors of Residential Happiness}

The correlation matrix between all variables and/or constructs in the model is presented in Table 2. Some moderate correlations are apparent, but there is no multicollinearity (Field, 2009). The results of the hierarchical regression are presented in Table 3. In step one, all relevant sociodemographic (sex, age income, ethnicity and marital status) were entered; in step two, the event variables were entered. While all $\mathrm{F}$ values for the models are significant (both in steps 1 and 2), they only predicted a very small portion in ratings of the reversed negative affects (SWB_Neg_R; model 3), and the presence of positive affects (SWB_Pos; model 4), respectively 6\% and 8\% of the variance in step 1 , and $7 \%$ and $8 \%$ in step 2 . The models better predicted the overall happiness (HAP_You; model 1), satisfaction with life (SATIS; model 2), for which respectively $15 \%$ and $23 \%$ is explained in step 1 , and $17 \%$ and $24 \%$ in step 2 .

Income significantly predicted all happiness variables in all models and each step, indicating that people with higher scores on perceived income are generally happier. Age significantly predicts overall happiness and reversed negative affect in step 1, and remains a significant predictor in step 2 for reversed negative affect. The age-coefficients are positive, indicating that older people score higher on these happiness constructs.

Adding events into the mix (step 2), only seemed relevant for predicting the one-item happiness variable: overall happiness (HAP_You; model 1), as only for this model, the change in $R^{2}$ was significant (from $15 \%$ to $17 \% ; \mathrm{p}<.05$ ). More specifically, respondents of both events groups, those who were aware of the OSG $(\beta=.13, \mathrm{p}<.05)$ and those aware of the $55+\mathrm{SG}(\beta=.16$, $\mathrm{p}<.05$ ) reported significantly higher levels of overall happiness (HAP_You) than the control group. This finding is important, as these results show that awareness of the two NMSE investigated, added significantly to feelings of overall feelings of happiness in a meaningful way. Of course, the causality cannot be confirmed here: are happier people more likely to be interested 
in sport, or do the events in this case, increase feeling of happiness? Note that the intention to attend did not significantly contribute to feelings of happiness.

\section{Discussion}

The purpose of this contribution was to explore if two NMSE affected the happiness of residents (non-attendees) in the host community, and if reports of happiness of host residents differed according to the type of event they were most aware about. The events under investigation were two multi-sport events: the 2014 Ontario Summer Games (for participants ages 13-20) and the 55+Summer Games (for participants ages 55 and older). Residents were intercepted in public spaces to fill out a survey, enquiring about their event awareness, their level of happiness, as well as socio-demographic variables, which are known to affect happiness. Based on the theoretical conception of SWB (Diener, 2000), a holistic approach was taken to measure happiness and well-being, as it provides a deeper understanding than the traditional oneitem measure.

The results confirmed previous findings that people with higher incomes tend to be happier (e.g., Downward \& Rasciute, 2011; Pawlowski et al., 2011; Rodriguez-Pose \& vonBerlepsch, 2014). The "U-shaped" relationship of age with happiness (e.g., Downward \& Rasciute, 2011; Kavetsos \& Szymanski, 2010; Rodriguez-Pose \& vonBerlepsch, 2014) was somewhat confirmed in that there was some evidence that older people in our sample showed significantly higher scores for reversed negative affects. Given that the average age of our sample was 37 years, and only people 18 years of age and older, were included in the sample it is not surprising that we did not find evidence for greater levels of happiness among younger people. We found no significant differences between any of the happiness constructs based on sex, ethnicity or marital status (e.g., Downward \& Rasciute, 2011; Kavetsos \& Szymanski, 2010; Rodriguez-Pose \& vonBerlepsch, 2014). 
We did find evidence that the two events under investigation added significantly to nonattendees' residential happiness in a meaningful way, but only for the one-item variable of "overall happiness". Adding the event variables in block 2 of the hierarchical regression accumulated $2 \%$ of additional variance to explain the overall happiness variable, and this change in $R^{2}$ was statistically significant. This provides support to measuring happiness with this oneitem only (e.g., Kavetsos \& Szymanski, 2010) when investigating these feelings in a broader context of hosting events and their impact on residents, outside the context of attending. This is in contrast with Diener's (2000) recommendation to take a holistic approach to measure happiness and well-being. More research is needed on different types of events, and events of different sizes to further validate the usage of the single item versus the holistic approach to measuring happiness and well-being of host residents in the context of events. Furthermore, the results showed that the two different types of NMSE did not affect residential happiness differently. If people were aware of these events, feelings of overall happiness were more apparent when compared to the control group. Of course, the causality cannot be confirmed. The question remains: are happier people more likely to be interested in sport, and thus more aware? Or do the events increase feeling of happiness?

The results provide support that residents experienced higher levels of happiness, merely by being aware that the two NMSEs were being hosted in the community, regardless of whether they attended the event or not. As was the case for multiple studies that investigated MSE (e.g., Gibson at al., 2014; Gursoy, Chi, Ai, \& Chen, 2011; Pranic, Petric, \& Cetinic, 2012; Kavetos \& Szymanski, 2010), feelings of belonging and community pride may trigger these feelings of happiness of non-attendee residents. 
Clearly, the general feelings of happiness measured here should not be confused with the higher levels of happiness residents may experience when actually attending an event (e.g., Hallman et al., 2013; Kuper \& Szymanski, 2012; Maennig \& Porsche, 2008; Mutter \& Pawlowski, 2014). Events create opportunities for pleasure and fun, keep individuals busy, develop and confirm identities (Mannell \& Snelgrove, 2011), and allow people to escape from their daily lives (Shipway \& Jones, 2007; Snelgrove et al., 2008), mechanisms which positively affect feelings of happiness. However, we did not collect reports of happiness among residents that were planning on attending the event(s). Thus, the residents in our study may have experienced enhanced feelings of happiness merely because they were aware of the locally hosted events, without necessarily intending to attend. Thus, it is possible that these NMSEs created "positive vibes" for those who were aware of their hosting. Future research should measure happiness of both event attendees and non-attendees to address this issue by directly comparing these groups of residents in the same context, thereby further unraveling the different mechanisms that trigger feelings of happiness.

From a practical point of view, it is important to make local residents aware that these events are being hosted, and emphasize community pride and belonging in the lines of media and advertising communication. Creating a festival atmosphere leading up to, and surrounding the events (e.g., Chalip, 2006), may capture the interest of residents; make them more aware that these are being hosted, and potentially make them happier, whether they are planning to attend or not.

The variance explained based on the variables in the hierarchal regression models $\left(R^{2}\right)$ was rather low, indicating that there are many more variables impacting happiness of individuals. Indeed, some authors have identified other external factors (Downward \& Rasciute, 2011; Forrest \& McHale, 2010), or select local and geographical conditions such as level of inflation or 
inequality, which both negatively affect happiness scores (Rodriguez-Pose \& vonBerlepsch, 2014). The fact, however, that both events were hosted in the same region and during the same summer, somewhat controls for these variations in local and geographic conditions. However, future research should include these variables in happiness analyses when possible.

\section{Conclusion}

Happiness was measured in a holistic way, and included four components of SWB: overall happiness, satisfaction with life, positive affects and reversed negative affects. It is recommended to research a wider variety of events to further validate the usage of the single item versus the holistic approach to measuring happiness and well-being of host residents in the context of events. Future research should continue to explore the relationship between sport events and happiness for a greater variety of events, both non-mega and mega-events like the Olympic Games and the FIFA World Cup, for which a holistic approach to measuring happiness has yet to be explored. Testing temporal effects, namely measuring levels of happiness pre-, during, and post-event will be essential to reveal if events significantly impact feelings of happiness among residents of host cities and/or nations. This will also allow for the investigation of whether feelings of happiness created through events are sustained long-term (e.g., Maennig \& Porsche, 2008).

In summary, in the context of the two NMSE under investigation, we found: (1) higher levels of happiness of aware, non-attendee residents, when measured with a single-item of overall happiness, but not for other measures of happiness in the holistic approach (causality can not be confirmed); (2) aware, non-attendee residents did not need to have the intention to attend the events to experience these higher levels of happiness; and (3) higher feelings of happiness of aware, non-attendee residents were not different according to the type of event. From a practical perspective, these findings stress the importance of informing residents of the hosting of these 
events so they become aware that these events are being hosted in their community. Effective communication should include feelings of pride and belonging, as these will stimulate feelings of happiness.

\section{Acknowledgement}

Human and Social Sciences Research Grants (HSSRG) form the University of Windsor and the Humanities, Social Sciences Research Council (HSSRC) of Canada, and Sport Canada for their financial support to conduct this study.

\section{References}

Brown, A. \& Massey, J. (2001). Literature review: The impact of hosting major sporting events. London: UK Sport.

Chalip, L. (2006). Towards social leverage of sport events. Journal of Sport Tourism, 11(2), 109127.

Connolly, M. (2013). Some like it mild and not too wet: The influence of weather on subjective well-being. Journal of Happiness Studies, 14, 457-473.

Davis, M.C. \& End, C.M. (2011). Team success, productivity and economic impact. In P. Rodriguez, S. Kesenne, \& B.R. Humphreys (Eds.), The economics of sport, health and happiness: The promotion of well-being through sporting activities ( $\mathrm{pp}$. 151-162). Northampton, MA: Edward Elgar Publishing, Inc.

Dewar, A. \& Kavussanu, M. (2011). Achievement goals and emotions in golf: The mediating and moderating role of perceived performance. Psychology of Sport and Exercise, 12, 525532.

Diener, E. (2000). Subjective well-being: The science of happiness and a proposal for a national index. American Psychologist, 1, 34-43. 
Downward, P. \& Rasciute, S. (2011). An economic analysis of the subjective health and wellbeing of physical activity. In P. Rodriguez, S. Kesenne, \& B.R. Humphreys (Eds.), The economics of sport, health and happiness: The promotion of well-being through sporting activities (pp. 33-53). Northampton, MA: Edward Elgar Publishing, Inc.

Field, A. (2009). Discovering statistics using SPSS ( $3^{\text {rd }}$ Edition). Thousand Oaks (Ca): Sage.

Forrest, D. \& McHale, I.G. (2011). Subjective well-being and engagement in sport: Evidence from England. In P. Rodriguez, S. Kesenne, \& B.R. Humphreys (Eds.), The economics of sport, health and happiness: The promotion of well-being through sporting activities (pp.184-199). Northampton, MA: Edward Elgar Publishing, Inc.

Gaffney, C. (2013). Between discourse and reality: The un-sustainability of mega-event planning. Sustainability, 5, 3926-3940. doi:10.3390/su5093926

Gibson, H., Walker, M., Thapa, B., Kaplanidou, K., Geldenhuys, S., \& Coetzee, W. (2014). Psychic income and social capital among host nation residents: A pre-post analysis of the 2010 FIFA World Cup in South Africa. Tourism Management, 44, 113-122.

Green, B. C. (2001). Leveraging subculture and identity to promote sport events. Sport Management Review, 4, 1-19.

Gursoy, D., Chi, C.G., Ai, J. \& Chen B.T. (2011). Temporal change in resident perceptions of a mega-event: The Beijing 2008 Olympic Games. Tourism Geographies, 13(2), 299-324.

Hallmann, K., Breuer, C., \& Kuhnreich, B. (2013). Happiness, pride and elite sporting success: What populations gain the most from national athletic achievements? Sport Management Review, 16, 226-235.

Han, S., Kim, H., Lee, E., \& Lee, H. (2013). The contextual and compositional associations of social capital and subjective happiness: A multilevel analysis from Seoul, South Korea. Journal of Happiness Studies, 14, 1183-1200. doi: 10.1007/s10902-012-9375-x 
Heere, B., Walker, M., Gibson, H.; Thapa, B.; Geldenhuys, S.; \& Coetzee, W. (2013). The power to unite a nation: the social value of the 2010 FIFA World Cup in South Africa, European Sport Management Quarterly, 13, 450-471.

Hopkins, D.J. \& King, G. (2010). Improving anchoring vignettes: Designing surveys to correct interpersonal incomparability. Public Opinion Quarterly, 74(2), 201-222.

Huang, H. \& Humphreys, B.R. (2011). Sports participation and happiness: Evidence from US micro data. In P. Rodriguez, S. Kesenne, \& B.R. Humphreys (Eds.), The economics of sport, health and happiness: The promotion of well-being through sporting activities (pp.163-183). Northampton, MA: Edward Elgar Publishing, Inc.

Inoue, Y., \& Havard, C. (2014). Determinants and Consequences of the Perceived Social Impact of a Sport Event. Journal of Sport Management, 28, 295-310.

Johnson, B., \& Whitehead, J. (2000). Value of public goods from sports stadiums: The CVM approach. Contemporary Economic Policy, 18(1), 48-58.

Joshanloo, M. (2014). Eastern conceptualizations of happiness: Fundamental differences with Western views. Journal of Happiness Studies, 15, 475-493. doi: 10.1007/s10902-0139431-1

Kahneman, D., Krueger, A.B., Schkade, D.A., Schwarz, N., \& Stone, A.A. (2004). A survey method for characterizing daily life experience: The daily reconstruction method. Science, 306(5702), 1776-1780

Kaplanidou, K., Karadakis, K., Gibson, H., Thapa, B., Walker, M., Geldhuys, S., \& Coetzee, W. (2013). Quality of life, event impacts, and mega event support among South African residents before and after the 2010 FIFA World Cup. Journal of Travel Research, 52(2): 631-645.

Kavetsos, G. (2011). Physical activity and subjective well-being: An empirical analysis. In P. Rodriguez, S. Kesenne, \& B.R. Humphreys (Eds.), The economics of sport, health and 
happiness: The promotion of well-being through sporting activities (pp. 213-222). Northampton, MA: Edward Elgar Publishing, Inc.

Kavetsos, G. \& Szymanski, S. (2010). National well-being and international sports events. Journal of Economic Psychology, 31(2), 158-171. doi: 10.1016/j.joep.2009.11.005

Klein, C. (2013). Social capital or social cohesion: What matters for subjective well-being? Soc. Indic. Res, 110: 891-911. doi: 10.1007/s11205-011-9963-х

Kuper, S. \& Szymanski, S. (2012). Soccernomics. New York, NY: Nation Books.

Littlejohn, M.; Taks, M.; Wood, L., \& Snelgrove, R. (submitted). Sport events and happiness: development of a measuring instrument. World Leisure Journal (Special Issue: Leisure and Happiness)

Littlejohn, M., Taks, M., Wood, L., \& Snelgrove, R. (2015). Sport events and happiness. (23nd EASM Conference; oral presentation; Dublin (Ir); Sept. 10, 2015)

Maennig, W. \& Porsche, M. (2008). The feel-good effect at mega sports events. Recommendations for public and private administration informed by the experience of the FIFA World Cup 2006. Hamburg Contemporary Economic Discussions, 18, 1-27.

Mannell, R. C., \& Snelgrove, R. (2011). Leisure and the psychological well-being and health of older adults. In H. Gibson \& J. Singleton (Eds.), Leisure, aging and well-being (pp. 143157). Champaign, IL: Human Kinetics.

Misener, K., Doherty, A., \& Hamm-Kerwin, S. (2010). Learning from the experiences of older adult volunteers in sport: A serious leisure perspective. Journal of Leisure Research, 42, 267-289.

Mutter, F. \& Pawlowski, T. (2014). The monetary value of the demonstration effect of professional sports. European Sport Management Quarterly, 14(2), 129-152. doi:10.1080/16184742.2014.882369 
Pawlowski, T., Breuer, C. \& Leyva, J. (2011). Sport opportunities and local well-being: Is sport a local amenity? In P. Rodriguez, S. Kesenne, \& B.R. Humphreys (Eds.), The economics of sport, health and happiness: The promotion of well-being through sporting activities (pp. 223-243). Northampton, MA: Edward Elgar Publishing, Inc.

Pranic, L., Petric, L. \& Cetinic, L. (2012). Host population perceptions of the social impacts of sport tourism events in transition countries; Evidence from Croatia. International Journal of Event and Festival Management, 3(3), 236-256.

Prince, J. (2013, October 11). Windsor to host 2014 Ontario Summer Games. The MediaPlex. Retrieved from: http://themediaplex.com/windsor-to-host-2014-ontario-summer-games/

Rodriguez, P., Kesenne, S., \& Humphreys B.R. (Eds.), The economics of sport, health and happiness: The promotion of well-being through sporting activities. Northampton, MA: Edward Elgar Publishing, Inc.

Rodriguez-Pose, A. \& von Berlepsch, V. (2014). Social capital and individual happiness in Europe. Journal of Happiness Studies, 15, 357-386. doi: 10.1007/s10902-013-9426-y

Schwarz, N. \& Clore, G.L. (1983). Mood, misattribution, and judgments of well-being: Informative and directive functions of affective states. Journal of Personality and Social Psychology, 45(3), 513-523.

Shipway, R., \& Jones, I. (2007). Running away from home: Understanding visitor experiences and behaviour at sport tourism events. International Journal of Tourism Research, 9, 373383.

Snelgrove, R., Taks. M., Chalip. L, \& Green, B.C. (2008). How visitors and locals at a sport event differ in motives and identity. Journal of Sport \& Tourism, 13(3), 165-180.

Snelgrove, R., \& Wood, L. (2010). Attracting and leveraging visitors at a charity event. Journal of Sport \& Tourism, 15, 269-280. 
Snelgrove, R., Wood, L., \& Havitz, M. (2013). The development of attachment to a physically active charity event. International Journal of Nonprofit and Voluntary Sector Marketing, 18, 133-140.

Taks, M. (2013). Social sustainability of non-mega sport events in a global world. European Journal for Sport and Society, 10(2), 121-141

Taks, M., Green, B.C., Misener, L., \& Chalip, L. (2014) Evaluating sport development outcomes: The case of a medium sized international sport event. European Sport Management Quarterly, 14(3); 213-237.

Taks, M., Wood, L., Snelgrove, R., \& Anderson, J. (2014). Hosting "Big" events in "Small” cities: An examination of socio-political discourse and residents' perceptions. In North American Society for Sport Management Conference Abstracts (pp. 514-515). Pittsburgh (PA): Duquesne University.

Thoits, P. A., \& Hewitt, L. N. (2001). Volunteer work and well-being. Journal of Health and Social Behavior, 42, 115-131.

Waddell, D. (2014, August, 7). Game on for 2014 Ontario Summer Games. The Windsor Star. Retrieved from: http://blogs.windsorstar.com/news/game-on-for-2014-ontariosummergames.

Walton, H., Longo, A., \& Dawson, P. (2008). A contingent valuation of the 2012 London Olympic Games: a regional perspective. Journal of Sports Economics, 9, 304-317.

Zhou, H. (2012). A new framework of happiness survey and evaluation of national well-being. Journal of Happiness Studies, 108, 491-507. doi: 10.1007/s11205-011-9888-4 
Table 1: Descriptive Statistics Overall, and of the Three Groups: OSG (aware of the Ontario Summer Games), 55+SG (aware of the $55+$ Summer Games), and the Control Group (unaware of events being hosted)

\begin{tabular}{|c|c|c|c|c|c|c|}
\hline & & \multirow[t]{2}{*}{ Overall } & \multirow[t]{2}{*}{ OSG } & \multirow[t]{2}{*}{$55+\mathrm{SG}$} & \multirow{3}{*}{$\begin{array}{l}\text { Control Group } \\
\qquad(\mathrm{n}=93)\end{array}$} & \multirow{3}{*}{$\mathrm{p}$} \\
\hline & & & & & & \\
\hline & & $(=321)$ & $(n=176)$ & $(n=52)$ & & \\
\hline Socio-demogr. Variables & Label & & & & & \\
\hline Age (Average \& $S D$ ) & (AGE) & $37(17)$ & $36^{(a)}(15)$ & $52^{\text {(b) }}(17)$ & $30^{(\mathrm{c})}(16)$ & $\mathrm{F}(2,318)=35.97 * * *$ \\
\hline Women (in \%) & $(\mathrm{SEX})$ & 58 & 60 & 52 & 59 & Chis-sq = 1.030 n.s. \\
\hline Income (Average \& SD) & & $3.68(1.24)$ & $3.69(1.22)$ & $3.77(1.23)$ & $3.62(1.22)$ & $\mathrm{F}(2,318)=0.237$ n.s. \\
\hline Caucasian (in \%) & & 77 & 73 & 87 & 77 & Chis-sq $=3.977$, n.s. \\
\hline \multicolumn{7}{|l|}{ Marital Status (in \%) } \\
\hline Single (in \%) & & 56 & 58 & 37 & 62 & Chis-sq $=9.777, *$ \\
\hline Married no kids (in \%) & & 11 & 10 & 17 & 8 & Chis-sq $=3.424$, n.s. \\
\hline Married with kids(in \%) & & 34 & 32 & 46 & 30 & Chis-sq $=4.429$, n.s. \\
\hline \multicolumn{7}{|l|}{ Event Variable } \\
\hline Attend (in \%) & & 27 & 28 & 44 & 13 & Chis-sq $=17.558, * * *$ \\
\hline \multicolumn{7}{|l|}{ Happiness Variables } \\
\hline Vignette & (HAP_Sam) & $5.26(0.71)$ & $5.20(0.68)$ & $5.44(0.85)$ & $5.26(0.66)$ & $\mathrm{F}(2,318)=2.385^{\mathrm{ns}}$ \\
\hline Overall Happiness & (HAP_YOU) & $4.88(0.91)$ & $4.92(0.89)$ & $\mathbf{5 . 1 5}^{(\mathrm{a})}(0.89)$ & $4.65^{(b)}(0.90)$ & $\mathrm{F}(2,318)=5.740 * *$ \\
\hline Satisfaction with life & (SATIS) & $3.18(0.56)$ & $3.18(0.57)$ & $3.29(0.54)$ & $3.12(0.56)$ & $\mathrm{F}(2,318)=1.537^{\mathrm{ns}}$ \\
\hline Reversed negative SWB & $\left(\mathrm{SWB} \_N E G \_R\right)$ & $3.69(1.24)$ & $3.60^{(\mathrm{b})}(1.22)$ & $4.11^{\text {(a) }}(1.09)$ & $3.62^{(b)}(1.31)$ & $\mathrm{F}(2,318)=3.724^{*}$ \\
\hline Positive SWB & (SWB_POS) & $4.50(1.05)$ & $4.52(1.05)$ & $4.46(1.16)$ & $4.47(1.31)$ & $\mathrm{F}(2,318)=0.118^{\mathrm{ns}}$ \\
\hline
\end{tabular}

Note. Post hoc Tukey (ANOVA): (a) (b) (c) are significantly different; $* \mathrm{p}<.05 ; * * \mathrm{p}<.01 ; * * * \mathrm{p}<.001$ 
Table 2: Correlation matrix ( $\mathrm{N}=321)$

\begin{tabular}{|c|c|c|c|c|c|c|c|c|c|c|c|c|}
\hline & 2 & 3 & 4 & 5 & 6 & 7 & 8 & 9 & 10 & 13 & 14 & 15 \\
\hline & SATIS & SWB_N & SWB_P & Age & Sex & Inc & Ethn & Single & MWK & OSG & $55+\mathrm{SG}$ & Attend \\
\hline 1. $\mathrm{HAP}_{-} \mathrm{YOU}$ & $.61 * * *$ & $.33 * * *$ & $.47 * * *$ & $.12 *$ & .08 & $.35 * * *$ & .04 & $-.14^{*}$ & $.11^{*}$ & .05 & $.14^{*}$ & .07 \\
\hline 2. SATIS & 1 & $.26 * * *$ & $.52 * * *$ & .06 & .00 & $.46 * * *$ & .04 & $-.17 * *$ & $.13^{*}$ & .00 & .09 & .05 \\
\hline 3. SWB_Neg_R & & 1 & $.20 * * *$ & $.18^{* *}$ & -.02 & $.16^{* *}$ & .05 & -.10 & .06 & -.08 & $.15^{*}$ & .06 \\
\hline 4. SWB_Pos & & & 1 & -.05 & $.08^{*}$ & $.24 * * *$ & -.05 & -.05 & .02 & .03 & -.02 & 0.07 \\
\hline 5. Age & & & & 1 & .09 & -.02 & $.11 *$ & $-.44 * * *$ & $.36 * * *$ & -.07 & $.41 * * *$ & .03 \\
\hline 6. Sex & & & & & 1 & -.05 & .09 & $-.12^{*}$ & .11 & .03 & -.06 & -.09 \\
\hline 7. Income & & & & & & 1 & -.02 & -.09 & .05 & .01 & .03 & .06 \\
\hline 8. Ethnicity & & & & & & & 1 & $-.26 * * *$ & $.19 * *$ & -.09 & .10 & $-.14 *$ \\
\hline 9. Single & & & & & & & & 1 & $-.80 * * *$ & .05 & $-.17 * *$ & .04 \\
\hline 10. Marr. w. kids (MWK) & & & & & & & & & 1 & -.04 & $.12 *$ & -.04 \\
\hline 11. OSG & & & & & & & & & & 1 & $-.48 * * *$ & .05 \\
\hline 12. $55+\mathrm{SG}$ & & & & & & & & & & & 1 & $.17 * *$ \\
\hline 13. Attend & & & & & & & & & & & & 1 \\
\hline
\end{tabular}

Note. $*=\mathrm{p}<.05 ; * *=\mathrm{p}<.01 ; * * *=\mathrm{p}<.001$ 
Table 3: Predictors of Residential Happiness (Hierarchical Regression Analyses: Step 1)

\begin{tabular}{|c|c|c|c|c|c|c|c|c|c|c|c|c|}
\hline & \multicolumn{3}{|c|}{$\begin{array}{c}\text { Model 1 } \\
\text { HAP_YOU }\end{array}$} & \multicolumn{3}{|c|}{$\begin{array}{l}\text { Model } 2 \\
\text { SATIS }\end{array}$} & \multicolumn{3}{|c|}{$\begin{array}{c}\text { Model 3 } \\
\text { SWB Neg R }\end{array}$} & \multicolumn{3}{|c|}{$\begin{array}{c}\text { Model } 4 \\
\text { SWB_Pos }\end{array}$} \\
\hline & $B$ & $S E B$ & $\beta$ & $B$ & $S E B$ & $\beta$ & $B$ & $S E B$ & $\beta$ & $B$ & $S E B$ & $\beta$ \\
\hline \multicolumn{13}{|l|}{ Step 1} \\
\hline Constant & $3.68 * * *$ & 0.29 & & $2.43 * * *$ & 0.17 & & $2.46 * * *$ & 0.41 & & $3.89 * * *$ & 0.34 & \\
\hline Age & 0.01 & 0.00 & $.11 *$ & 0.00 & 0.00 & 0.02 & 0.01 & 0.01 & $.17 * *$ & -0.01 & 0.00 & -.08 \\
\hline \multicolumn{13}{|l|}{ Sex } \\
\hline Male (=ref.) & & & & & & & & & & & & \\
\hline Female & 0.14 & 0.10 & .08 & 0.00 & 0.06 & 0.00 & -.07 & 0.14 & -.03 & 0.21 & 0.12 & .10 \\
\hline Income & 0.26 & 0.04 & $.35^{* * * *}$ & 0.21 & 0.02 & $0.45^{* * *}$ & 0.17 & 0.06 & $.17 *$ & 0.21 & 0.05 & $.24 * * *$ \\
\hline \multicolumn{13}{|l|}{ Ethnicity } \\
\hline $\begin{array}{l}\text { Non-Caucasian (=ref.) } \\
\text { Caucasian }\end{array}$ & 0.03 & 0.12 & .01 & 0.02 & .07 & .02 & 0.09 & 0.17 & .03 & -0.15 & 0.14 & -.06 \\
\hline \multicolumn{13}{|l|}{ Household Status } \\
\hline Single & -0.09 & 0.17 & -.05 & -0.11 & 0.10 & -.10 & 0.12 & 0.24 & .05 & -0.04 & 0.20 & -.02 \\
\hline Married with kids & 0.03 & 0.17 & .01 & 0.03 & 0.10 & .02 & 0.16 & 0.24 & .06 & 0.13 & 0.20 & .06 \\
\hline $\begin{array}{r}R^{2} \text { for Step } 1 \\
F(6,314) \text { for Model } 1\end{array}$ & & $\begin{array}{l}.15 \\
.99 * * *\end{array}$ & & & $\begin{array}{c}.231 \\
15.72 * * *\end{array}$ & & & $\begin{array}{l}.06 \\
3.28 * *\end{array}$ & & & $\begin{array}{l}.078 \\
4.43 * * *\end{array}$ & \\
\hline
\end{tabular}


Table 3 (cont'd)

Predictors of Residential Happiness (Hierarchical Regression Analyses: Step 2)

\begin{tabular}{|c|c|c|c|c|c|c|c|c|c|c|c|c|}
\hline & \multicolumn{3}{|c|}{ HAP_YOU } & \multicolumn{3}{|c|}{ SATIS } & \multicolumn{3}{|c|}{ SWB_Neg_R } & \multicolumn{3}{|c|}{ SWB_Pos } \\
\hline & $B$ & $S E B$ & $\beta$ & $B$ & $S E B$ & $\beta$ & $B$ & SE B & $\beta$ & $B$ & $S E B$ & $\beta$ \\
\hline \multicolumn{13}{|l|}{ Step 2} \\
\hline Constant & $3.59 * * *$ & 0.30 & & $2.42 * * *$ & 0.18 & & $2.054 * * *$ & 0.43 & & $3.84 * * *$ & 0.36 & \\
\hline Age & 0.00 & 0.00 & .03 & 0.00 & 0.00 & -.01 & 0.01 & 0.00 & $.14 *$ & -0.01 & 0.00 & -.09 \\
\hline \multicolumn{13}{|l|}{ Sex } \\
\hline Male (=ref.) & & & & & & & & & & & & \\
\hline Female & 0.17 & 0.10 & .09 & 0.01 & 0.06 & .01 & -.05 & 0.14 & -.02 & 0.22 & 0.12 & .10 \\
\hline Income & 0.25 & 0.04 & $.34 * * *$ & 0.21 & 0.02 & $.45 * * *$ & 0.17 & 0.06 & $.16 * *$ & 0.20 & 0.05 & $.24 * * *$ \\
\hline \multicolumn{13}{|l|}{ Ethnicity } \\
\hline $\begin{array}{l}\text { Non-Caucasian (=ref.) } \\
\text { Caucasian }\end{array}$ & 0.03 & 0.12 & .01 & 0.02 & 0.07 & .02 & 0.08 & 0.17 & .03 & -0.13 & 0.14 & -.05 \\
\hline \multicolumn{13}{|l|}{ Household Status } \\
\hline Married no kids (=ref.) & & & & & & & & & & & & \\
\hline Single & -0.08 & 0.17 & -.04 & -0.11 & 0.10 & -.10 & 0.12 & 0.24 & .05 & -0.04 & 0.20 & -.02 \\
\hline Married with kids & 0.05 & 0.17 & .03 & 0.03 & 0.10 & .03 & 0.17 & 0.24 & .07 & 0.14 & 0.20 & .06 \\
\hline \multicolumn{13}{|l|}{ Event Perspective } \\
\hline OSG & 0.23 & 0.11 & $.13 *$ & 0.04 & 0.07 & .04 & -0.10 & 0.16 & -.04 & 0.04 & 0.13 & .02 \\
\hline $55+\mathrm{SG}$ & 0.40 & 0.17 & $.16 *$ & 0.11 & 0.10 & .07 & 0.20 & 0.24 & .06 & 0.02 & 0.20 & .01 \\
\hline $\begin{array}{l}\text { Attend (intention) } \\
\qquad \text { No (= ref.) }\end{array}$ & & & & & & & & & & & & \\
\hline
\end{tabular}




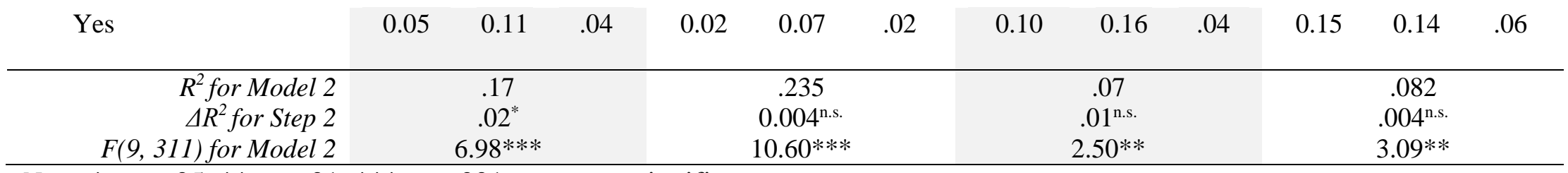

Note. $*=\mathrm{p}<.05 ; * * \mathrm{p}<.01 ; * * * \mathrm{p}<.001 ; \mathrm{n} . \mathrm{s} .=$ not significant 